\title{
Tropas de Refresco. Ensayo de historia literaria patria
}

Fernando Curiel Defossé

Seminario de Edición Crítica de Textos, IIFL, unam

REsumen: Este ensayo aborda dos historias fronteras, la Literaria y la Intelectual. Propone y argumenta los principales aspectos de la historia intelectual que contribuirían a la realización institucional de la pendiente historia de la literatura mexicana.

Aвstract: Essay, the present work addresses two borderline Histories, the Literary and the Intellectual. Proposes and arguments aspects of this last one that will contribute to the institutional production of the pending History of Mexican Literature.

Palabras Clave: historia literaria; historia intelectual; humanidades; Instituto de Investigaciones Filológicas; Revolución mexicana; periodización del siglo xx literario.

KeYwords: Literary History; Intellectual History; Humanities; Philological Researches Institute; Mexican Revolution; Periods of the Twentieth Century Literature.

Fecha de ReCerción: 21 de abril de 2015

FECHA DE ACEPTACIÓN: 25 de agosto de 2015

Para Aurora Ocampo

When I came out of my collapse...

Edmund Wilson

Acercarse a los procesos culturales desde distintos escorzos, requiere de un ejercicio diorámico de observación que permita ubicar, de la manera más certera, a hombres y circunstancias, a obra y propósitos y, por eso mismo, explique los ejes vertebrales de una nación.

A. E. Díaz Alejo 


\title{
I. CAMPo DE MANiobras
}

\section{Objetivo}

\begin{abstract}
A spira este ensayo - de ahí su título - llamar, a la historia intelecA tual, en auxilio de la historia literaria; concretamente, de la historia de la literatura mexicana. Enfoque que juzgo pertinente en la discusión de las condiciones de posibilidad de una tarea institucional a la fecha postergada.

En efecto, el del decurso de las letras mexicanas constituye una asignatura pendiente, todavía al día de hoy, en los trabajos del Instituto de Investigaciones Filológicas. Una década después de la creación del Centro de Estudios Literarios —episodio del que me ocuparé más adelante-, en 1966, se comprometió su factura como culminación de los afanes hasta entonces cumplidos alrededor de la lengua y la literatura mexicanas. Ahora bien, pese al tiempo transcurrido, dicha promesa peca aún de incumplimiento. Y corre ya la segunda década del siglo XXI.
\end{abstract}

Aunque todavía en construcción, lo admito, la historia intelectual enfatiza aspectos que estimo determinantes para la pesquisa del proceso literario nacional, ya se ocupe de los cuatro siglos transcurridos desde la Conquista, ora ajuste el objetivo al período novohispano o virreinal, ya destaque siglos en particular — de preferencia el xviII, el XIX o el Xx. ${ }^{1}$

Anticipo, sin embargo, que sea cual fuere la temporalidad elegida - hay perspectivas de larga, mediana y corta duración—, la disciplina y método aquí invocados, aunque parezca paradójico, no se agotan en

${ }^{1}$ El Instituto de Investigaciones Filológicas, a través del Centro de Estudios Literarios, ha emprendido la factura de una "Historia de las literaturas en México. Siglo XIX y xx"; que, más que en el relato total de los fenómenos literarios nacionales, descansa, principalmente en el análisis de sus procesos. Aplaudo, sobre todo, la temporalidad conjunta XIX y xx. Sin desdoro de las literaturas precolombina y novohispana, determinantes para nuestra visión, una entre otras, es la conformación del México moderno y contemporáneo que data de una decisión, en su arranque política y jurídica, y más tarde económica, ideológica y mental: la Independencia de España; el paso de colonia de una metrópoli europea, a estado-nación de América. Sin embargo, aclaro, esta inquisición se centra en el siglo xx literario nacional: 1898-2000. Lo de 1898 es porque adscribo al siglo xx el Modernismo, principio de la emancipación de la literatura nacional. 
la actividad intelectual en la que se inscribiría la textual de la literatura. Sólo que se ha convenido en llamarla historia intelectual para diferenciarla de historias afines, la de las mentalidades, la de las ideas y la cultural, de modo señalado. Lo que no obsta, empero, para coincidencias e intercambios.

Por el contrario, la historia intelectual, respecto a la literatura, además de asumirla como totalidad — agentes, agencias—, indagaría las circunstancias individuales y colectivas de su realización. De ahí el acento en, respectivamente, las biografías y las generaciones. Al tiempo que se reconocería la literatura como dominio simbólico —al igual que las Artes o el Derecho-, para la comprensión cabal del fenómeno lo dividiría en sus elementos constitutivos: creación, producción, distribución, recepción, certificación, conservación. Idéntica relevancia concedería a las formas y redes de sociabilización (véase primera parte de Curiel 2007: 21 ss.). Por último, la historia literaria indagaría los vasos comunicantes de la literatura con otros órdenes simbólicos. Para nuestro país, primordialmente, la educación, las artes todas y la política.

\section{Principales aspectos}

Para resumir, cuatro serían los aspectos esenciales a la historia intelectual que a mi juicio podrían contribuir a la factura de una historia de la literatura mexicana. Los enumero:

- Sincronía y diacronía.

- Texto y contexto.

- Orden y subversión.

- Sistema complejo.

Si el primer aspecto comunica el pasado con el presente, provocando visiones del futuro, y el segundo examina los muy concretos condicionamientos de la poesía y la prosa; el tercero aborda las tensiones, tradición y ruptura, continuidad y disrupción, que contienden al interior de una literatura específica, mientras el cuarto comprende los ríos — diversos afluentes y corrientes- que confluyen al mar de signos. 
De tales efectivos, incorporados a la campaña de historiar la literatura mexicana, hablo cuando hablo de Tropas de refresco.

\section{Historias literarias}

En la medida en que la historia intelectual, como adelanté, no se constriñe a una historia del gremio intelectual, de su habla y costumbres, sino, más bien, tiene por objeto una de las producciones simbólicas de la sociedad, la literatura; de las tres especies de historias literarias posibles, la de los autores, eminentemente de orden psicológico — y aún psicoanalítico-, la de obras maestras y la del sistema literario, aquí se privilegia la citada en último término. Lo que nos lleva a hablar, más que de una historia literaria, de historia de la literatura.

Toda vez que el foco de atención no se ancla en autores y obras particulares, por de avanzada que sean los autores e innovadoras las obras — sin que se rehúya la genialidad-; se autoriza hablar de autor social, combinación de poética personal y ambiente. Pongo un ejemplo. No escapa a Ernst Robert Curtius, en su asedio penetrante y perdurable a James Joyce, la atención a "las fuerzas que sobre él han obrado": la familia en vilo, Irlanda desgarrada, la educación jesuítica, el exilio interior, el destierro final (123 ss.). Obra señera y circunstancias.

Tal el meollo de nuestra argumentación.

Partes

Anticipado lo anterior, participo que el ensayo consta de cinco partes interconectadas.

En la primera, se pesquisa la investigación literaria institucional, que en definitiva conduce a la creación del Instituto de Investigaciones Filológicas (IIFL, I973), precedida por la del Centro de Estudios Literarios (CEL, 1956). Esto en el contexto de un amplio marco compuesto por: la sucesión de propuestas teóricas entre 1956 y el presente; los principales episodios, en el mismo período, de la patria literatura; y las actas de defunción expedidas a la novela, a la literatura en general, a la historia $\mathrm{y}$ a las humanidades.

Entiendo el reparo. ¿¿Por qué traer a cuento a la historia y a las humanidades? En primer término, porque literatura e historia, junto con la 
filosofía, conforman el "núcleo duro" de las humanidades, entendidas en su más senequista raíz: cultivo de lo humano. $\mathrm{Y}$, en segundo, porque los cuestionamientos -endógenos y exógenos- de la historia y de las humanidades, han contribuido, en no poca medida, a la crisis de la propia literatura. Hoy por hoy sometida, no a las leyes de la estética verbal, sino a las del mercado editorial. ${ }^{2}$

La segunda parte, con algún detalle, dado el tema principal que nos ocupa - historia literaria más historia intelectual—, examina la muerte y resurrección de la historia. Su decurso en etapas que van: de verdad inconcusa a instrumento del Poder al servicio del statu quo, y, en seguida, de Poética a ciencia aproximada del pasado. Con sus precisas reglas e instrumentos.

La tercera parte, derivada de la previa, se detiene en el contexto seminal del siglo xx mexicano en general y de las letras en particular: la Revolución mexicana. ${ }^{3} \mathrm{Y}$ no sólo por informar una particular corriente narrativa y artística, sino por alzarse como florecimiento, deformación, traición e incluso des-instauración, del acontecimiento mayor que permea la vida nacional. Y de cuya historiografía repasaremos no sólo su arranque testimonial, oficialismo esclerótico y reformismo infecundo, sino, asimismo, las bases de una nueva historia que proponemos a discusión. ${ }^{4}$

La cuarta parte se demora en la crisis de las Humanidades.

${ }^{2}$ Otro factor a considerar es el tecnológico, de extraordinaria relevancia en la investigación literaria e, inclusive, en la creación lírica y narrativa. Capítulo especial requeriría la escritura electrónica vía la PC, el e-mail, el twitter, la lectura asimismo electrónica vía el e-book, la videograbación del acontecer vía el iphone y el ipad, la consulta ilimitada y sin restricciones de saberes — literarios, humanistas, artísticos, sociales, científicos, técnicos- vía el Internet, la factura y la multiplicación de conocimiento vía Google, y la multiplicación de fondos documentales vía impresoras y scanners. A lo que había que agregarse, para una visión completa, la facilidad democrática de registrar papeles, párrafos, citas, portadas, calles, edificios, etcétera, con los simples celulares mudados artilugios fotográficos y cinematográficos. Y en cuanto a límites que impone la distancia, ya se populariza el dron.

${ }^{3}$ Contexto histórico, me temo, cuadre o no, asimismo del siglo XxI en curso incierto.

${ }^{4}$ Propuesta de la que ofrecí un adelanto en el diálogo sostenido con Javier Garciadiego el 3 de octubre de 2014, con motivo de la presentación del citado proyecto "historia de las literaturas en México". 
La quinta parte se afana en los puntos de mayor y productiva intersección entre historia literaria e historia intelectual, poniendo el énfasis, por nuestro lado, en elementos de una notable riqueza en las letras del siglo Xx. Aludo a generaciones, a redes de sociabilidad, y a revistas.

Por último, expongo, en el sentido de "petición razonada" del vocablo, una propuesta de periodización del siglo xx literario mexicano. Propuesta, anticipo, que no se reduce a los solos cortes temporales, siempre en relación con los correspondientes a la historia general del país, sino que implica una triple operación interconectada. Pregunta sobre el ciclo o período; pregunta sobre los grupos en contienda - un sistema literario es campo de fuerzas, o no lo es-; pregunta sobre manifiestos - estéticos, educativos, políticos, sociales. En combate, pues, épocas, grupos y concepciones.

Tales son los contextos actuales, e imbatibles, de la creación escrituraria, de la inquisición histórica y de los vuelos humanísticos - golondrinas escasas que no hacen verano. En otras palabras, de los evidentes o secretos vasos comunicantes entre las letras, la historia y las humanidades. Las tres objeto de demolición o, de plano, declaración de muerte. ${ }^{5}$

\section{LAS LETRAS}

\section{UNAM literaria}

El estatus universitario de las letras coagula, como ya avancé, en $1956 .^{6}$ Lo anterior, merced al Centro de Estudios Literarios (CEL) que, originado en la Facultad de Filosofía y Letras, pronto se adscribe a la Coordinación de Humanidades, su hábitat natural y, en 1973, da pie, en un conjunto mayor, al Instituto de Investigaciones Filológicas.

${ }^{5}$ Cito tres lecturas ineludibles. Para las letras: Alvin Kernan, La muerte de la literatura, Caracas, Monte Ávila Editores, 1996; para la historia: Keith Windschuttel, The Killing of History, New York, The Free Press, 1977; y para las humanidades, Carlos García Gual, Sobre el descrédito de la literatura y otros avisos humanistas, Barcelona, Península, 1999.

${ }^{6}$ Concepto, el de Letras, que había sufrido para el momento, un rebautizo. Bellas Letras, en la Edad Clásica; literatura más adelante, debido sobre todo al imperio de la grafía, la letra; Texto a partir de nociones estructuralistas. 
En el marco de su desarrollo, al presentarse la oportunidad de mudar de Centro a Instituto el CeL, se duda llamarlo Instituto de Investigaciones Literarias o Instituto de Investigaciones Filológicas. A la postre se impone el segundo título. La empresa tiene nombre y apellido: Rubén Bonifaz Nuño.

No sobra reiterar su misión: lengua, literatura y culturas hispánicas, clásicas y amerindias. Magma de la singularidad mexicana — que no pocas ocasiones se ignora o, peor todavía, se desdeña.

Como tampoco sobra la mención de los momentos de la investigación humanística universitaria en la que la filológica ocupa su sitio institucional. Llamativa historia de fundaciones pares. Primero fueron, en los treinta, la investigación social y la estética; luego, en los cuarenta, la económica y la histórica; en los sesenta, la filosófica y la jurídica; y, al fin, en los setenta, la filológica y la antropológica. ${ }^{7}$

Tornando al CEL, no faltó, cabe subrayarlo, a la buena nueva divulgada por la Gaceta de la UNAM el 24 de septiembre de 1956 — hace la friolera de 59 años—, ni más ni menos que la creación de un Centro de Estudios Literarios, el parangón — que suscribo en sus términos- entre los estudios críticos y teóricos. En "modo diferente", pero creativos, ambos, a fin de cuentas. La crítica y la teoría literarias - y la historia y la filología - son, o deberían ser, igualmente, literatura.

Atinada, orientadora, programática resultó empero, la separación en dos aguas del mar escriturario: creación, interpretación. Figuras tutelares de la interpretación de las letras para el CEL, lo eran, a la sazón, Julio Jiménez Rueda, José María González de Mendoza, Francisco Monterde y José Luis Martínez, principalmente. ${ }^{8}$

${ }^{7}$ Sobre la investigación en humanidades, jalonada primero por Institutos mono disciplinarios y más tarde, exigencia de los tiempos, por Centros y Programas multidisciplinarios, véase Curiel 2001a, particularmente "La investigación investigada".

${ }^{8}$ Apenas se presta atención a la circunstancia — ¿fortuita? ¿dictado de la época?de que Jiménez Rueda publica una historia de la literatura mexicana, el mismo año, 1928, que Carlos González Peńa publica la suya; tenida como única, solitaria e insuperable hasta el día de hoy. / "El Abate" había trabajado en Europa al lado del diplomático Jaime Torres Bodet y fungía como devoto propagandista de un autor señero con un pie en el Modernismo y otro en la Vanguardia, José Juan Tablada y, en 1931, había dado a los tórculos una Antología de la prosa en México. / Francisco Monterde, con antecedentes, al igual que Jiménez Rueda, en el Neocolonialismo, se ocupaba, generoso, de figuras, generaciones y revistas. / De Martínez, que será invitado como asesor del CEL, 


\section{Contextos, momentos}

Hacia 1956, la escena literaria mexicana, natural y fatalmente ceñida a la ciudad de México, y dentro de la ciudad de México al territorio que se dilataba - unas cuantas hectáreas cargadas de historia - entre el extremo oriente de la Alameda central y Correo Mayor, la pueblan, si ya no figuras del Positivismo y del Modernismo, sí un puñado de ateneístas, algunos de los Siete Sabios, varios Estridentistas y Contemporáneos, gente del 14 y del 29 y de Medio Siglo; y sobrevivientes de las batallas, ismos ideológicos al rojo vivo, de las décadas de los veinte y los treinta; exilados españoles y centroamericanos. Irrumpían, de otra parte, algunos personeros de la generación de la Casa del Lago.

Lugares de la memoria: Bellas Artes; pérgolas de la Alameda - librería y galería-; librerías Porrúa y Robredo; Escuela Nacional Preparatoria en San Ildefonso; hoteles Del Prado, Ritz y Reforma; cine Alameda y cine París; café París y Tupinamba y demás ruidosos cotos del transtierro republicano. En esencia, la capital que congelará Salvador Novo en una de sus más redondas crónicas de la ciudad de México. ${ }^{9}$

En 1947 se había publicado Al filo del agua de Agustín Yáńez, novela con el antecedente preclaro de La sombra del caudillo (1929, ¿novela? ¿historia? ¿inusitado experimento?), que inaugura entre nosotros la modernidad narrativa, la que arranca con Joyce, Proust, Musil, Wolfe. En 1949, empieza a circular el primer suplemento asimismo moderno: México en la Cultura, del periódico Novedades. Larga será la historia de uno de sus directores —el otro lo era Miguel Prieto-, Fernando Benítez, en el periodismo cultural. Prieto inicia, a su vez, una fecunda escuela de diseño gráfico.

En 1955, un año antes de la creación del CEL, nace, bajo la tutela de Octavio Paz, y la co-responsabilidad de Emmanuel Carballo, recién importado de Guadalajara, y Carlos Fuentes, ya autor de Los días enmascarados, la Revista Mexicana de literatura. Mensajera del cambio, la ruptura, en términos de contienda: nacionalismo con toques de realismo social —o de plano, socialista— versus cosmopolitismo. Una nueva

se contaba con "Algunos problemas de la historia literaria" (1940), literatura mexicana del siglo XX (1949) y Problemas literarios (1955).

${ }^{9}$ Véase S. Novo. Nueva grandeza mexicana, en Toda la prosa. México: Empresas Editoriales, 1964. 
generación, la ya citada de Medio Siglo, comienza a desplegarse a partir de Ciudad Universitaria - territorio sureño de la ciudad letrada — inaugurada en los estertores del alemanismo.

En 1959, año que resiente la pérdida de José Vasconcelos, Genaro Fernández MacGregor y Alfonso Reyes — de la primera línea del Ateneo sólo quedaban Guzmán y Torri-, abre sus puertas, con escasos recursos, pero bajo la dirección entusiasta e imaginativa de Juan José Arreola, la Casa del Lago, en el hermoso edificio construido en 1908 por José Ives Limantour, como Automóvil Club. El campus regresaba a la polis. ${ }^{10}$

La específica creación literaria la tejen, principalmente, Martín Luis Guzmán, Salvador Novo, Jaime Torres Bodet, Agustín Yáñez, José Revueltas, Octavio Paz, Juan José Arreola, Juan Rulfo, Emilio Carballido, el primer Carlos Fuentes, Rosario Castellanos, Luis Spota, Rafael Solana, entre otros.

Durante los cincuenta — década, afirma Carballo, sin la que no se entiende la siguiente-, tienen verificativo tres movimientos, uno intelectual y dos artísticos, de señalada importancia y efectos de larga duración. Aludo, respectivamente, a Hiperión, Poesía en Voz Alta y —en sus comienzos- La Ruptura.

Activo entre 1948 y 1952, Hiperión conforma un movimiento ocupado en discernir la filosofía de lo mexicano. ${ }^{11}$ Poesía en Voz Alta, por su parte, cuyo primer programa se realizó en 1953, significó una exitosa experimentación literaria, teatral, escenográfica y musical escénica. ${ }^{12} \mathrm{La}$ Ruptura, como su nombre lo presume, declara hostilidades a la hegemónica plástica mexicana que había impulsado el muralismo. "Cortina de nopal". ${ }^{13} \mathrm{Al}$ albear los sesentas surgirá el grupo Nuevo Cine.

${ }^{10}$ La Casa del Lago se convertirá en uno de los más intensos focos de la revuelta cultural de los sesentas; revuelta en varios planos: literatura, teatro, música, cine, danza, pensamiento crítico. También alojará a la generación que sigue a la de Medio Siglo, con la que, erróneamente, suele confundírsele.

${ }^{11}$ Nombres: Alfonso Reyes, Leopoldo Zea, Jorge Portilla, Emilio Uranga, Luis Villoro, Salvador Reyes Nevares, Fausto Vega, Joaquín Sánchez MacGregor. Véase El Hiperión 2006.

${ }^{12}$ Nombres: Juan José Arreola, Octavio Paz, Héctor Mendoza, José Luis Ibáñez, Leonora Carrington, Juan Soriano, Joaquín Gutiérrez Heras.

${ }^{13}$ Nombres: José Luis Cuevas, Lilia Carrillo, Fernando García Ponce, Manuel Felguérez, Vicente Rojo, Gironella, Vlady. 
Contrariamente a las predicciones urbanísticas —urbanismo en pañales-, que la suponía crecer hacia el norte, la ciudad de México se desplaza hacia el sur, jalonada, a partir de 1952, por la Ciudad Universitaria. Si bien en el centro, hacia 1956 o el 57, se funda otra extensión de la ciudad letrada, la Zona Rosa.

\section{La reflexión literaria}

Con el CEL se inicia la singularización universitaria de los estudios literarios. En 1960, ocupa la planta baja de la Biblioteca Central, cabe la explanada.

En 1961, se privilegia, dentro del CEL, el seminario como forma de trabajo académico. En 1964, a los originales objetivos de investigación y docencia, se agrega, de modo expreso, la difusión. En 1966 se plantean algunas transformaciones: el paso de Centro a Instituto y, y ya como Instituto de Investigaciones Literarias, su adscripción, en vez de a la Facultad de Filosofía y Letras, a la Coordinación de Humanidades. Respecto a nuestro tema central, la historia de la literatura mexicana, se reconoce que "hasta la fecha hace falta, pues sólo se han escrito algunos manuales escolares, los cuales por su concreta finalidad didáctica no tienen la profundidad y amplitud requeridas por una obra de esta importancia" ("Filología literaria", en Clark y Curiel: 89). No sin reconocerse lo avanzado en la edición de antologías y ensayos monográficos, de panoramas, de la reedición de textos fundamentales de las patrias letras.

El largo proceso, lo adelanté ya, se resuelve el 4 de octubre de 1973, con la aprobación, por parte del Consejo Universitario, de Instituto de Investigaciones Filológicas; especie de federación compuesta por el Centro de Estudios Literarios, el Centro de Lingüística Hispánica, el Centro de Estudios Clásicos y el Centro de Estudios Mayas. Escisión del CEL, surgirá el Seminario de Poética y a la tradicional división, griega y latina, se añade el Neo Latín o Latín Mexicano; lustros después surgen el Seminario de Edición Crítica de Textos y el Seminario de Hermenéutica. 


\section{Corrientes en rejuego}

A reserva de más detenidas exploraciones, puede afirmarse que, agotada la impronta del existencialismo y sus implicaciones literarias, culturales, políticas, dos cuerpos doctrinarios pujan, para emplear una expresión reciente a la luz del superficial reformismo en boga, por la "predominancia". Una, sajona; gala la otra. La "Anglo theory" y la "French theory". Teorías pero también modas, y en tanto tales, de temporada. Además, del lado soviético, soplaron poderosos los vientos del Formalismo, del Círculo de Praga y del batjinismo. Se desplazaron, firmes icebergs, la lingüística y la semiótica. Luego vendrían los Estudios Culturales, variopintos; la Narratología que pasa sin pena ni gloria; la sin duda fecunda Teoría de la Recepción; las fugaces propuestas Neocolonialista y Subalterna. Temporadas de estructuralismo y neoestructuralismo, textualismo e hipertextualismo, poéticas y semiosis, literaturas menores, neomarxismo y neoretórica. Fruto no siempre fecundo de la problematización de lo literario, del pensar la literatura, ha sido la ya mencionada suplantación de poesía y prosa, textos originales, por la abstracta teorización. Una de las consecuencias, deplorables, consistió en la interdicción, de un lado, de ricos y definitorios materiales que por comodidad llamo Papelería privada — manuscritos, archivos—; y, de otro, de la literatura del Yo integrada por diarios, epistolarios, autobiografías, memorias, entrevistas de fondo, historias de vida. Hoy por hoy finalmente revaloradas por los estudios literarios, revaloración que no dudo en llamar conquista laboral de quienes nos ocupamos de tiempo atrás de tales asuntos.

\section{Compatriota incómodo}

Puede afirmarse que, en el siglo xx, mientras Edmundo O'Gorman piensa la historia, Alfonso Reyes piensa la literatura. Para 1956, tres años antes de su muerte, a la edad de 70 años, el hijo del general Bernardo Reyes tenía publicada una extensa obra de teoría, crítica, historia, filología y aún filosofía literarias; de la literatura literaria y de la literatura subsidiaria; del teatro, de la novela policiaca y de la novela "bodegón", de la autobiografía y del periodismo, revistas y periódicos. De sus talentos de filólogo había dado pruebas durante los años ma- 
drileños, 1914-1924, y a partir de su regreso definitivo a México en 1939. En la primera etapa, investigador del Centro de Estudios Históricos de Madrid, sección Filología, ocúpase de la edición crítica de clásicos hispánicos; en la segunda, ocúpase de la edición crítica de su propia vasta obra. De la que alcanzó a ver publicados diez volúmenes y dejar preparados tres.

No sobra, a fe mía, el recuento de asedios críticos y teóricos alfonsinos que nacen con la obra de creación. Ni más ni menos que 12 de los 26 tomos de sus obras completas, sobresaliendo, por su liviandad sustantiva, La experiencia literaria y, por su ambición y complejidad, $E l$ deslinde. Títulos a los que menester es añadir trabajos que con anticipación se inscriben en lo que hoy por hoy se considera historia intelectual. Narración de la constelación de la que se forma parte, de su contexto y manifiestos; de la literatura propia, considerada horizontal y verticalmente; de la obra y sus circunstancias; del obsequio y desobediencia del canon; del complejo sistema simbólico literario y cultural. Me refiero a Pasado inmediato e historia documental de mis libros. ${ }^{14}$

Pues bien: pese al abundoso, excepcional conocimiento literario desplegado por Alfonso Reyes antes y durante la implantación de la investigación literaria universitaria, su lectura, influencia, luces, resultan nulas en el componente crítico-teórico del Centro de Estudios Literarios. Deuda impagada de modo inexplicable.

\section{Muertes y resurrecciones}

En esta suscinta contextualización del surgimiento y desarrollo del Centro de Estudios Literarios, toca su turno a las ocasiones y circunstancias, en que se ha decretado la muerte de géneros literarios ancestrales. Sobresale, sin lugar a dudas, el caso de la novela, género mayor.

Al momento de la creación del CEL, por ejemplo, se había decretado la muerte de la novela decimonónica y de la vanguardista del siglo xx, por un grupo encabezado por Alain Robbe-Grillet y Michel Butor. Propaganda de una era del recelo que dio - pensó ilusoriamente que daba - jaque mate a los fundamentos de la novela francesa y

${ }^{14}$ A la fecha preparo la edición crítica, por vez primera en libro independiente, de historia documental de mis libros para El Colegio de México. 
rusa. La escrita por Stendhal, Flaubert, Balzac, Dostoyievski, Tolstói. Pero jaque mate también de la novelística practicada por Joyce, Proust, Woolf, Dos Passos, Scott Fitzgerald, Hemingway, Faulkner.

Mentís al doblar de campanas de la Nueva Novela Francesa y su poética de cosificación, objetividad, trasiego de laboratorio textual, lo fue, en México, la aparición de Casi el paraíso, Sol de octubre, El llano en llamas y La región más transparente. Y, en Hispanoamérica, la configuración del Boom! o Nueva Novela Latinoamericana, de la que ocuparon la punta del pelotón Carlos Fuentes, Mario Vargas Llosa, Julio Cortázar y Gabriel García Márquez; y, el grueso, José Donoso, Cabrera Infante, Manuel Puig, entre otros - sin faltar el trazo genealógico dilatado lo mismo a Juan Carlos Onetti que a Alejo Carpentier.

Además de la renovación, el aire fresco, vivificante, que en su momento aparejó el New Journalism norteamericano, de inmediato traducido al español. Tributo, en el campo periodístico, a las armas y recursos ancestrales del cuento y la novela. Incursiones por demás logradas de Tom Wolfe, Truman Capote, Gay Talese, Hunter S. Thompson, Norman Mailer.

De cualquier manera, ciertos componentes de la Nouveau roman hallarán eco en escritores como Sergio Fernández, Vicente Leñero, Julieta Campos y Salvador Elizondo; en tanto, su indudable ímpetu experimental, lo hará en la generación de La Onda.

\section{Muerte de la literatura}

Estructuralismo, giro lingüístico, New criticism, Deconstrucción y Posmodernidad, por citar las modas interpretativas más recalcitrantes, minaron los cimientos en los que por siglos se levantó el edificio monumental de las letras; joyel de las humanidades. En otro sitio me ocupo de la cuestión, más honda, que apareja el triunfo irrebatible de las ya mencionadas leyes del mercado, en particular la rentabilidad (véase "Hipótesis" y "El lugar" en Curiel 2007: 11-19).

El automatismo del lenguaje expulsó del texto al escritor, al autor, a la trama y al personaje. La hiper-textualización borró los ricos contextos. La negación de los grandes relatos eliminó la inteligibilidad y el sentido de poemas, cuentos, novelas. La literatura, significante, podía significar cualquier significado. En consecuencia, desaparecieron la ge- 
nealogía de los géneros, las condiciones sociales y estéticas de la literatura y sus actores.

\section{LA HISTORIA}

\section{Hechos, representaciones}

No basta, sostengo, para empezar, la ya admitida separación entre Story e History, sin duda ocurrente, sino aducir —sustantiva-, la que existe entre historia e historiografía. La primera, acontecer, mezcla de tiempo y hechos. La segunda, escritura, mezcla de signos y teorías. Como tampoco sobra el distingo, subrayado en la introducción de una obligada antología, entre metodología y método. La primera multánime, decidida por la bandera ideológica del autor: marxista, formalista, positivista, idealista, cliométrica; o posmoderna o neocolonialista. El segundo: invariable, en tanto que define procedimientos y técnicas de investigación (véase Matute 1972).

Dos pasos: heurística y hermenéutica; que en realidad son tres gracias a la escritura. Representación interpretativa de acontecimientos.

\section{Punto de inflexión}

El 68 francés, el más publicitado sobre el checo o el mexicano, no sólo tomó calles y plazas —aquí, Reforma, Juárez, el Zócalo, la mortífera plaza de las Tres Culturas en Tlatelolco-, también asoló los espacios intramuros - aulas, cubículos, laboratorios. Suelo acudir al colega Jean Chesneaux, como ejemplo emblemático de la revisión, desde dentro, del nexo entre la producción académica y los Poderes. Ahora que, mientras en otras latitudes, la "contestación" en su vertiente democratizadora se llevó al seno familiar, a la fábrica, al campus, en México derivó a la más superficial de las democracias políticas: la electoral. Origen de la singular mixtura actual de desencanto público, partidocracia y desmedido gasto y burocracia electorales. 


\section{Caso emblemático}

Las marcas de la agonía y nuevo amanecer de Chesneaux, se inscriben en uno de sus libros de mayor venta, lo mismo en París que en la ciudad de México. ${ }^{15}$ Sin rebozo, suelta el autor:

Este ensayo sobre el saber histórico está escrito por un profesional (in) confortablemente instalado en su cátedra y su situación. Sin embargo, ambiciona ir más allá de las reflexiones generales sobre la historia que publican no pocos "colegas" desde hace algunos ańos, siempre en el interior del discurso intelectual y del "territorio" del historiador (7).

Imagino la unánime aquiescencia en el medio, la mirada autocrítica a estanterías repletas, salones de conferencias, jardines acotados; la compartida necesidad de salir, física y mentalmente, del confort; de preguntarse, con el autor, sobre el "lugar" del saber histórico en, ya no el conocimiento sino "la vida social". Preguntarse, en fin, si elabora un producto jerarquizado que va del especialista al consumidor de historia; si actúa a favor o en contra del orden establecido; si su saber enraíza en una "necesidad colectiva". Etcétera, etcétera. Pues bien: todas estas cuestiones, precisa Chesneaux, "son políticas". Y se orientan "a la lucha revolucionaria".

Tres son las fuentes del anterior viraje: el marxismo creativo a lo Gramsci; las experiencias por contradictorias que resulten de la revolución china; y el ultra izquierdismo occidental, léase New Left norteamericana y "posmayo francés".

¿Hacer tabla rasa del pasado? Sí. Pero a condición de romper los automatismos del conocimiento histórico, a saber: el corte cronológico por periodos, la afición por el tiempo verbal pasado, la autoridad de la letra impresa, la disociación entre documento y problema, la lectura a-crítica.

${ }^{15}$ Aludo a ¿Hacemos tabla rasa del pasado? A propósito de la historia y de los historiadores. Traducción de Aurelio Garzón del Camino. México: Siglo XXI, 1976. 


\section{Muertes de la historia}

Toda proporción guardada, pero sin olvidar, en lo general, que literatura e historia fueron consideradas ramas frondosas del mismo árbol; ni de que, en el concepto de Chesneaux de autoridad a cuestionar, está junto a la letra impresa el autor — novelista, historiador-; podemos afirmar que el acta de defunción expedido a la novela, tiene su parangón en la historia.

Si ya la Escuela de los Anales dio por difunta la forma tradicional de historiar - historia política, historia diplomática, historia de próceres - abriendo el espacio al economista, al geógrafo, al sociólogo, al demógrafo, etcétera, planteamientos sostenidos a lo largo de sus diferentes etapas y directores, la disciplina se ramificó en diversas si no es que encontradas vertientes. De las que destaco dos principalísimas: la historia como arma del poder; la historia como poética.

Si la primera vertiente la representa, tal como acabamos de verlo, abrumadoramente, Jean Chesneaux, la segunda tiene por adalides, de modo señalado, a Michel de Certeau y a Hayden White. ${ }^{16}$ Quienes, en esencia, centran la atención en la historiografía, escritura de la historia, hasta el extremo de disociar verdad y expresión, fondo y forma. Asuntos - estructura, partes, morfología, componentes del discurso-, reconozcámoslo, propios de los estudios literarios. De los estudios y de la creación literaria. ¿O cómo justipreciar, amén de su contenido epistemológico, este pasaje de de Certeau?:

La historia hace hablar al cuerpo que calla. Supone un desfasamiento entre la opacidad silenciosa de la "realidad" que desea expresar y el lugar donde produce su discurso, protegida por la distancia que la separa de su objeto (Gegenstand). La violencia del cuerpo no llega hasta la página escrita sino a través de la ausencia, por medio de los documentos puedo ver en una playa donde... (16-17).

Etcétera, etcétera.

${ }^{16}$ Véase, respectivamente, Michel de Certeau. La escritura de la historia. Traducción de Jorge López Moctezuma. México: Universidad Iberoamericana, 1985; y Hayden White. Metahistoria. La imaginación histórica en la Europa del siglo XIX. Traducción de Stella Mastrangelo. México: Fondo de Cultura Económica, 1992. 
Inimaginable, este estilo elusivo, metafórico, "poético" podría decirse, en la escritura historiográfica tradicional.

El plan de ataque de White, por su parte, no da lugar a confusiones, al distinguir en el relato histórico dos niveles. Uno exterior o explícito integrado por los conceptos teóricos esgrimidos; otro, profundo o implícito decidido por "las posibilidades de prefiguración tropológica del campo histórico contenidas en el lenguaje poético en general" (II). Subrayo: no la perspectiva teórica o conceptual; no las fuentes primarias y secundarias; no el documento y el archivo. El lenguaje, lenguaje poético.

Al historiador, precisa White, lo cińen los géneros de la novela, la comedia, la tragedia y la sátira; las argumentaciones formalista, organicista, mecanicista y contextualista; y las ideologías del anarquismo, el conservadurismo, el radicalismo y el liberalismo. ¿No ocurre lo mismo con el narrador? Forma, no fondo; retórica —o neo retórica- no proposición científica (9-12). Tengo al historiador White como un imaginativo y digno de atención crítico y teórico de la literatura.

\section{La cosa es más grave}

En estos ajustes profundos, radicales, de la historia, que la convierten, ora en arma del poder, ya en poética; posiciones hay que de plano niegan la "decibilidad" misma del pasado. Obra de demoledora influencia, al igual que en los Estudios Literarios, de la French Theory, en particular de Jacques Derrida, Jean Baudrillard y Jean-François Lyotard. Tal es el caso del norteamericano Keith Jenkins. ${ }^{17}$

Contamos, afirma Jenkins, con dos historias, una "con mayúscula" y la otra "con minúscula". La primera, digamos la ortodoxa marxista o la Whig inglesa, considera a la disciplina histórica como aquella que asigna al pasado significación objetiva; cuando en realidad se ocupa de acontecimientos "contingentes". De lo que se trata es del uso del pasado para impulsar un determinado punto de vista. La segunda, de índole académica, pretendidamente profesional, objetiva e imparcial, se quiere estudio desinteresado del pasado en sí mismo y en sus propios

${ }^{17}$ Véase K. Jenkins. ¿Por qué la historia? Traducción de Stella Mastrangello Puech, revisión técnica de Germán Gómez. México: Fondo de Cultura Económica, 2006. 
términos; cuando en realidad resulta tan ideológica como la primera, toda vez "que toda historia es siempre para alguien" (12).

Que quede claro que el pasado no existe, no "históricamente", no más allá de las apropiaciones "textuales y constructivistas" que llevan a cabo los historiadores; lo que le impide al pasado tener independencia propia. En otras palabras, por

irreductible, terco, doloroso, cómico o trágico que pueda haber sido el pasado, sólo llega hasta nosotros mediante dispositivos de ficción que lo dotan de una gama de lecturas altamente selectivas y jerárquicas que "siempre están al servicio de poderes e intereses diversos". En consecuencia, el pasado como historia siempre ha estado y siempre estará necesariamente configurado, envuelto en tropos, figurado en tramas, leído, mitologizado e ideologizado en formas que nos resulten convenientes (12-13).

Ante tamaño aserto, cabe la dura pregunta: ¿para qué una historia de la literatura mexicana bi-secular, XIX y Xx, o sólo del Xx, si ya sabemos que la van a dictar quién sabe qué poderes, qué mitos, qué ideologías?

\section{Resuelta defensa}

Contra lo anterior se yergue, terminante, desde Australia, lejos, muy lejos de las pasarelas en las que luce sus galas la French Theory, el historiador Keith Windschuttle, en un libro intitulado sin rebozo The Killing of History, y en cuya portada se advierte su anti-revisionista materia: "How literary critics and social theorists are murdering our past". ${ }^{18}$

Tenemos que la historia, la Filosofía y las Matemáticas constituyen aportaciones de la antigua Grecia a la especie humana; que la primera lleva más de 2,400 años tratando de registrar la verdad sobre el pasado, esto es, describir lo mejor posible what really happened, que desde entonces los historiadores han estado sometidos a insuficiencias y errores, que su críticos refieren invariablemente a un real pasado insuficiente o erróneamente interpretado. Pero dicho panorama cambia de manera radical en la última década del siglo xx. Cito:

${ }^{18}$ Libro de 1977, editado por The Free Press de New York, y sobre cuya pista me puso Virginia Guedea. 
In the 1990s, the newly dominant theorists within the humanities and social sciences assert that is impossible to tell the truth about the past or to use history to produce knowledge in any objective sense at all. They claim we can only see the past through the perspective of our own culture and, hence, what we see in history are our own interests and concerns reflected back at us. The central point upon which history was founded no longer holds: there is no fundamental distinction any more between history and myth (Windschuttle: 1-2).

Este asalto frontal a los cuarteles de la historia tradicional - a la historia y a la Historiografía asumo yo-, se da en tres frentes: el de críticos literarios y cientistas - así les dio por llamarse en los setentas a los teóricos sociales-, metidos a historiadores; el de historiadores que cambian de bando; y el de historiadores tradicionales que incorporan a sus trabajos la buena desestabilizadora nueva. Contra todo esto, Windschuttle predica que la historia puede ser estudiada objetivamente, vaya, que el pasado existe, y que no obran obstáculos filosóficos para el objetivo de lograr "truth and knowledge about the human world" (2-3). Y para predicar con el ejemplo, se ocupa de historiar distintos episodios del pasado: de la conquista española de México a la batalla de Quebec en 1759, pasando por el asentamiento europeo en Australia, su tierra, y la caída del comunismo en 1989.

Sobra decir que comulgamos con el autor citado. Máxime que su idea de la historia entronca con las Humanidades. Pero soy de la idea de una atenta, dialéctica lectura crítica de los autores franceses estructuralistas y deconstructivistas, desestabilizadores de la literatura; en suma, de un cuidadoso y paciente rebusque, lo que se traduciría en hallazgos e iluminaciones. Que por supuesto abundan.

\section{LAS HUMANIDADES}

\section{Presentación}

La de las Humanidades es una plaza asediada desde muchos frentes. Me limito a México. Veamos. Divinización de la tecnología — que, lo reconozco, en ocasiones obra milagros. Victoria casi absoluta de las ganancias. El éxito ipso facto y su desprecio del esfuerzo. La cosificación. 
La banalidad como ethos. Esto por lo que se refiere a los valores, en un dominio cuya raíz, lo avancé, es el cultivo de lo humano.

Infravaloración del cultivo de la tradición grecolatina y neolatina; anacronismo y desánimo, salvo excepciones, en las instituciones cuyos fines son la pesquisa, la instrucción y la vulgata de disciplinas humanísticas; paulatina eliminación, frontal o a medias, descarada o edulcora$\mathrm{da}$, en los planes y programas de enseńanza media y superior, de materias nodales para el conocimiento humanístico, tales como la retórica y la filosofía; saberes literarios, históricos, filosóficos, estéticos, jurídicos, encapsulados y digeridos vía motores de búsqueda; la extinción de no pocos notables humanistas sin el decisivo relevo generacional; extinción, también, o larga agonía, de la lectura, la de fondo que es también un placer y no la de voraz y veloz esparcimiento. Todo esto por lo que se refiere a la institucionalidad. Lejos, muy lejos, queda el entusiasmo, utópico si se quiere, que levantó la inauguración de la Escuela Nacional de Altos Estudios y su ambicioso programa humanista que empezaba por la restitución de los dańos causados por el positivismo: enseńanza plena de la literatura, de la filosofía, de la historia, de las bellas letras. Quizá de eso se trate: ausencia de entusiasmo.

\section{Experto en descréditos}

A finales de los noventa del pasado siglo, Carlos García Gual, humanista español de excepción, publica un libro abocado al descrédito de la literatura y de las humanidades y de su territorio nutricio: la educación. ${ }^{19}$ Malas nuevas de este hoy desmemoriado, de competencia desalmada, cultura desechable, fetiche del gadget y el outfit y el selfie, en estado bélico de civilizaciones. No se dice, pero, por la fecha de aparición del libro, conjeturo - diría Borges, uno de los clásicos modernos comentados - la esperanza, por varios compartida, de que el inminente 2000 aparejaría un cambio de dirección aproada a mares promisorios.

Sin advertirlo, pero era de esperarse, el autor centra su prólogo en la lectura; la lectura "y sus avatares". Lógica abrumadora. No sobra decir que, en la lectura —y no en su suplantación "google"—, y en el diálogo — no en la asamblea amañada y manipulada—, descansa la literatu-

${ }^{19}$ Véase C. García Gual. Sobre el descrédito de la literatura y otros avisos humanistas. Barcelona: Ediciones Península, 1999. 
ra y con la literatura el cultivo humanista. ¿Generación emblemática mexicana? El Ateneo de la Juventud: 1909; luego Ateneo de México: 1912-1929 aproximadamente. La que más se le asemeja, la de Medio Siglo, se inclina por las ciencias sociales, el otro ramal componente de las humanidades contemporáneas. Hablar, entre nosotros, de humanidades, es hacerlo de humanidades y ciencias sociales.

\section{Aventura personal}

Llámese, al gusto del lector, viaje, excursión, introspección. Importan dos condiciones para la lectura: que sea personal y que sea silenciosa. Sin ellas, se pierde el sentido radical, y raigal, del trato con los grandes libros, antiguos o de esta mańana, patrimonio de todos. Pero algo falla si la íntima, apartada lectura, no lleva al convencimiento de lo indestructible de las aventuras de Ulises, el griego y el dublinense. Como si el iceberg que, en la helada noche Atlántica, da caza al Titanic, al embestir, en vez de un boquete por el que escapará una época de progreso tecnológico arrogante, abriera un surtidor de palabras e imágenes aleccionadoras. En la falta del tal convencimiento, descansa en no poca medida la crisis, creciente, de las humanidades.

Y cuidado con la superchería del tradicionalismo y del nacionalismo —-más grave aún, criminales si son religiosos. Al tradicionalismo hay que distinguirlo de la tradición. Y al nacionalismo del ser nacional. Tradicionalismo: "beatería ideológica de pesada retórica y efectos perniciosos que, al fijar como modelo eterno una interpretación del pasado, esclerotiza la fuerza educadora de la tradición — que se renueva de modo constante" (García Gual: 37). Tradición: renovación, relectura, dialéctica del pasado con el presente. Nacionalismo: infecundo tradicionalismo. Ser nacional: amor lúcido, crítico, a la nación propia.

Pues bien: a la tomografía que García Gual practica sobre el descrédito de la literatura y de las humanidades, en una sociedad utilitaria y neo-positivista, banal hasta extremos adictos, ¿qué remedios ofrece? Sin sustituir la experiencia del comercio directo con su libro, subrayo dos tipos de medicamentos. Los que se derivan de la lectura de un libro ajeno y los derivados de la experiencia de la imaginación narrativa, en sus aspectos individual y gregario. 


\section{Leamos, leamos}

¿Qué autor elige, en un amplio catálogo, García Gual? ¿A un filólogo como Amado Alonso? ¿A un filósofo metido a teórico de la literatura como Paul Ricoeur? ¿A un historiador que cojea del mismo pie como Michel de Certeau? No. A un crítico cinematográfico; un "diletante", no un "pedante": David Denby. Quien, llegado al cincuentenario de su edad, en edad de retiro, en lugar de algún hobby doméstico, regresa a la Universidad para leer, de tiempo completo, a los clásicos; experiencia que, periodista al fin, plasma en Los grandes libros (1997). Tres lecciones deriva don Carlos: la lectura del repertorio clásico como personal aventura; el refuerzo de la noción de indestructibilidad de los grandes libros; y, por último, la apertura de un diálogo permanente: con los libros leídos y con el presente.

\section{El contar}

De su especial interés es una medicina que, paradójicamente ignoran, o no la plantean con el vigor y rigor y claridad con que lo hace García Gual, los expertos en el discurso: escritores, críticos, teóricos, semiólogos o pedagogos - que los hay de talento. ¿Qué sanación? El contar y escuchar historias; quehacer traducido como "imaginación narrativa", y que compromete lo mismo a la literatura que a la educación. Cito, gustoso: "La dimensión narrativa de la cultura que se transmite en la educación es esencial en la formación intelectual y sentimental a partir de la niñez (es decir, de todos). Vivimos en una mundo contado por otros".

¿Y en cuanto a la institucionalidad, la política pública educativa? Cito de nueva cuenta:

También para los pueblos es esencial tener a la mano historias sagradas o profanas, venerables o frívolas, que expliquen el mundo y den un sentido humano a la existencia. O como escribió $\mathrm{H}$. Blumfeld de los mitos primigenios, relatos que den al mundo entorno subjetivo y "significatividad", es decir, sentido humano.

En las culturas arcaicas ese aspecto educativo lo proporcionaba la mitología (34-35). 
Honda contribución, oral o escrita, de la literatura a las humanidades, su alma mater.

Podemos, debemos anticipar, como lectura por demás aleccionadora y estimulante, la de una historia de la literatura mexicana, o historia de las literaturas en México, facturada con todas las de la ley: rigurosa y generosa en su metodología y en su método, multidisciplinaria, literaria e intelectual. Narración de mundos que nos han contado otros: Martín Luis Guzmán, Ramón López Velarde, Juan José Arreola...

\section{LA REVOLUCiÓN MEXICANA}

\section{Llamada}

Con su horno: el porfiriato; sus dos oleadas: la de 1910 y 1914; su contrarrevolución: 1913-1914; la construcción del Nuevo Estado: $1917-$ 1940; su pos-revolución: 1940-1968; y su des-instauración: 19682000; la Revolución mexicana informa el escenario estelar constante, en el que se inscriben las letras del siglo xx mexicano. En ella se inspira una de las corrientes de mayor fama, incluso internacional, que reúne a autores como Mariano Azuela, Martín Luis Guzmán, Rafael F. Muñoz, Nellie Campobello, Mauricio Madgaleno, etcétera; y, en una versión moderna, a Elena Garro, Carlos Fuentes y Jorge Ibargüengoitia.

Como en los casos de la Novela y de la historia, algunos autores, auto-promovidos como revisionistas, han decretado, asimismo, su muerte. Parte del impulso que se afanó, me place decir que en vano, a desproveer a la historia como History y como Story de todo contenido ficcional, imaginario, mítico, fabuloso. Tarea iconoclasta, pero no alegre sino enfurrunada, a causa de la cual por poco y nos quedamos sin La Virgen de Guadalupe, La Noche Triste, El Pipila, Los Niños Héroes, Zapata y Villa, héroes legendarios. Ignorando, pese a su condición de doctores en la disciplina, posgrados obtenidos en Europa y Estados Unidos, que tales contenidos forman parte de la historia y deben ser conocidos y valorados — no deturpados- por la Historiografía. 


\section{Nueva historia revolucionaria}

No es este el lugar para un repaso de las literaturas, la histórica y la narrativa, de la Revolución mexicana. Sus momentos, coincidencias, acuerdos, disparidades y desacuerdos. Sus pasos, desde el énfasis testimonial, pasando por la crítica de sus traiciones y deformaciones, su verdad oficial, su revisión, hasta la preeminencia del discurso sobre los acontecimientos. Por ahora, remito a los competentes recuentos, en tanto historia, de Javier Garciadiego; en cuanto historiografía, de Álvaro Matute; y en cuanto bibliografía literaria, de Fernando Tola de Habich.

Lo inconcuso es que al igual que sucedió con la literatura, con la novela y con la misma disciplina histórica, la tormenta demoledora y devastadora ha remitido.

\section{Nueva historia}

Post-facciosa y post-revisionista, la Nueva historia de la Revolución mexicana, el gran contexto de la prosa y la poesía del siglo xx, interrogaría, básicamente, las siguientes cuestiones:

- Principio o principios y final o finales.

- ¿Una o varias Revoluciones?

- Especies: política, agraria, obrera, cultural, regional.

- Gama de oposiciones al Viejo Régimen: de prensa, política, electoral, cultural, armada.

- Estética revolucionaria integrada por caricatura, corridos, novela, pintura, teatro, cinematografía, etcétera.

- Mínimo rimero.

VI. ÚLTIMOS REFUERZOS

Recapitulación

Sostengo que la historia intelectual brinda asideros sólidos para el abordaje de la historia literaria. En otro sitio, como señalé ya, ofrezco un 
elenco de los principales historiadores intelectuales, europeos, estadounidenses e hispanoamericanos. Por ahora, me limito a enfatizar ciertas aportaciones que cobran jugoso significado en un proyecto de historia literaria nacional.

La importancia que Robert Darnton asigna a las "tradiciones literarias"; sustento de procesos complejos del texto y del contexto.

El compendio que ofrece un libro más o menos reciente de François Dosse, que pone en la mesa los avances, las trabas, los caminos despejados y las promesas de la historia intelectual; dando todo su peso a las redes, los "conectores", los archivos personales, los períodos, la noción de campo intelectual como zona de conflictos, la perspectiva generacional. ${ }^{20}$

El sistema de fronteras que, para Carlos Altamirano, reviste el texto literario. De suerte que la reconstrucción de la literatura demanda conectarla con: la historia de las ideas, la historia política, la historia de las élites y la historia literaria misma. ${ }^{21}$

Planteamiento, el reciente, al que yo añado dos fronteras más: la específica historia generacional, que no se satisface con la de las élites, y el entendimiento de la ciudad como ese espacio de acción de los grupos y las tendencias.

En resumidas cuentas, la alianza conceptual entre las dos historias, literaria e intelectual, construye el enfoque multidisciplinario y poliédrico al que insta una literatura nacional. Aunque a partir de estos supuestos:

a) El retorno trepidante a los estudios literarios, de los expulsados por estructuralistas y deconstructivistas: del escritor con señas de

${ }^{20}$ Véase F. Dosse. La marcha de las ideas. historia de los intelectuales, historia intelectual. Traducción de Rafael F. Tomás. Valencia: Universitat de Valencia, 2007. El historiador francés compareció ante el Seminario de Investigación sobre historia y Memoria Nacionales, del que formo parte; comparecencia que remató con una larga entrevista, aún inédita, realizada por Antonio Sierra.

${ }^{21}$ Véase C. Altamirano. Para un programa de historia intelectual y otros ensayos. Buenos Aires: Siglo XXI Editores Argentina S.A.: 16. 
identidad al sentido —empezando por el estético— de poesías y narraciones.

b) El justo valor de la generación como autor colectivo; de lugares y redes de sociabilidad literaria; de revistas y polémicas; de filias y fobias.

c) Las intersecciones, para México definitorias, de literatura y poder, literatura y educación, literatura y sistema de las artes.

En consecuencia, fundidas generaciones y figuras señeras, puestos en relieve períodos y manifiestos y medios de expresión — las revistas en primer término-; suelo dividir el siglo xx literario patrio —hipótesis de investigación y docencia-, en determinados ciclos. En el entendido que tales cortes, con tentativos principios y finales, se enciman, traslapan, yuxtaponen. Helos aquí: Modernización (1898-1921); Vanguardias (1921-1934), Neonacionalismo (1934-1947); Neomodernización (1940-1968), y Contemporaneidad (1968-2000). Desde luego tengo presente que durante el segundo ciclo, Vanguardias, se dilata la modernización que aparejó el Ateneo e irrumpe la propaganda nacional del vasconcelismo educativo. Por citar un ejemplo. Y que no se trata de un desarrollo, todo él lineal, progresivo. Estancamientos y retrocesos están al día.

\section{Conclusión}

Atrás han quedado la suplantación de la obra creativa, y de la crítica, por la insaciable teoría; las insostenibles muertes de la novela, de la literatura, de la historia, de las humanidades; las corrientes pulverizadoras de la literaturnost; la "indecibilidad" del pasado, todo pasado, incluso el literario.

Sobreviven, en cambio, en el negocio editorial, la rareza de la apuesta estética sobre el binomio costo-beneficio, que ha pasado del 5\% tradicional al $25 \%$ o más, al impulso de la mercadotecnia y la publicidad; la oportunidad perdida, en el centenario de la Revolución mexicana, de un florecimiento de conceptos, de nuevos enfoques, de rescate documental y archivístico; la crisis de identidad social de las Humanidades; y la urgencia, para el Instituto de Investigaciones Filológicas, de cumplimentar la historia — historias — de la mexicana literatura. 
Termino apuntando que, a las realidades inéditas, que fundan poesía y prosa, la historia intelectual las discierne y sazona en su contexto y temporalidad.

\section{BibliografíA}

Chesneaux, Jean. ¿ Hacemos tabla rasa del pasado? Traducción de Aurelio Garzón del Camino. México: Siglo XXI Editores, 1997.

Clark de Lara, Belem y Fernando Curiel Defossé (coords.). Filología mexicana. México: Universidad Nacional Autónoma de México. Instituto de Investigaciones Filológicas, 2001.

Curiel Defossé, Fernando. La Universidad en la calle. México: Factoría Ediciones, 2001.

Curiel Defossé, Fernando. Elementos para un esquema generacional aplicable a cien años (aprox.) de literatura patria. México: Universidad Nacional Autónoma de México. Instituto de Investigaciones Filológicas, 2001.

Curiel Defossé, Fernando. sigloveinte@lit.mex.Amplio tratado de perspectiva generacional. México: Universidad Nacional Autónoma de México, 2007.

Curtius, ERnst R. "James Joyce y su Ulyses", en Ensayos críticos acerca de la literatura europea, t. II. Traducción de Eduardo Valenti. Barcelona: Seix Barral, 1959.

De Certeau, Michel. La escritura de la historia. Traducción de Jorge López Moctezuma. México: Universidad Iberoamericana, 1985.

EL HIPERION. Introducción y selección de Guillermo Hurtado. México: Universidad Nacional Autónoma de México. Programa Editorial de la Coordinación de Humanidades, 2006.

García Gual, Carlos. Sobre el descrédito de la literatura y otros avisos humanistas. Barcelona: Península, 1999.

Jenkins, Keith. ¿Por qué la historia? Traducción de Stella Mastrangelo. México: Fondo de Cultura Económica, 2006.

Kernan, Alvin. La muerte de la literatura. Caracas: Monte Ávila Editores, 1996.

Matute, Álvaro. México en el siglo XIX. Antología de fuentes e interpretaciones históricas. México: Universidad Nacional Autónoma de México, 1972.

Novo, Salvador. Nueva grandeza mexicana. México: Empresas Editoriales, 1964.

White, Hayden. Metahistoria. La imaginación histórica en la Europa del siglo XIX. Traducción de Stella Mastrangelo. México: Fondo de Cultura Económica, 1992.

Windschuttle, Keith. The Killing of History. New York: The Free Press, 1977. 